\title{
An Algorithm for Full Coverage and Real Time Traffic Density Calculation on Roads
}

\author{
Juma Joram Mashenene ${ }^{1}$, Xuewen Ding ${ }^{2}$, Said Kassim Katungunya ${ }^{3}$ \\ ${ }^{1}$ Tianjin University of Technology and Education, Electronics Department, \\ Tianjin Hexi District, Da Gu South Road 300222, China \\ ${ }^{2}$ Tianjin University of Technology and Education, Electronics Department, \\ Tianjin Hexi District, Da Gu South Road 300222, China \\ ${ }^{3}$ Tianjin University of Technology and Education, Electronics Department, \\ Tianjin Hexi District, Da Gu South Road 300222, China
}

\begin{abstract}
Intelligent traffic light systems are vital on assuring a realistic control and smooth flow of vehicles on the roads. For many years various systems had been proposed to solve various challenges related to vehicle traffic control. With all those efforts the traffic light systems in place as of now are inefficient and unrealistic due to the fact that most of the proposed solutions they failed to acknowledge the fact that coverage area of their systems is a vital player towards realistic systems, most of them are confined to traffic light junctions neighborhood. We propose an algorithm that increases surveillance coverage area to entire road segments and evaluates the incoming and outgoing vehicle traffic from the various road segments and at any given point of time it ensures that the exactly number of vehicles on the various road segments is known and this information is coupled to the timing subsystem for the evaluation of the time slot for various road segment on that round. The proposed algorithm together with its environmental setup will improve the efficiency vehicle traffic flow on our roads due to its realistic nature.
\end{abstract}

Keywords: Intelligent traffic light systems, Vehicle traffic flow, Vehicle traffic density

\section{Introduction}

The number of vehicles on the road increases day by day therefore for the best utilization of existing road capacity, it is important to manage the traffic flow efficiently. Traffic congestion has become a serious issue especially in the modern cities. The main reason is the increase in the population of the large cities that subsequently raise vehicular travel, which creates congestion problem [1-5]. Due to traffic congestions there is also an increasing cost of transportation because of wastage of time and extra fuel consumption [2]. Traffic jams also create many other critical issues and problems which directly affect the human routine lives and sometime life loss [6-8]. For example if there is an emergency vehicle like ambulance on the road with the critical patient on board. In that situation if an ambulance gets stuck in a heavy traffic jam then there are high chances that the patient cannot reach the hospital on time. So it is very important to design an intelligent traffic system which controls traffic intelligently to avoid accidents, collisions and traffic jams [7-8]. The most common reason of traffic congestion in third world countries is an inefficient traffic signal controlling which affects the traffic flow. For example if one lane has less traffic and the other lane with huge traffic but the duration of green light for both lanes is same then this is the waste of available resources and is inefficient. By considering the above example if the lane with higher traffic density should switch on the green signal light for a longer period than the lane with lesser density. Traffic flows are complex in nature as they have various varying parameters such as time of the day, day of the week, time of the year, nature of vehicles and infrastructure in place. The traffic lights systems put in place to control those traffic flows inherits such complex parameters and adds the cascaded dependent flow of vehicles, this is the situation in which the operations of one traffic light system depends on the operation of the adjacent traffic light system. Traffic light optimization is a complex problem. Even for single junctions there might be no obvious optimal solution. With multiple junctions, the problem becomes even more complex, as the state of one light influences the flow of traffic towards many other lights [11].

\section{Methodology}

Traffic light control system is a cascaded operational system on which the effectiveness of one subsection or lane creates challenges to the next subsection or lane. In order to have smooth flow of traffic, a concise consideration should be taken to address this cascading nature of the system. On a four way subsection and 8 roads traffic light, we divide the lanes into feeders and drainers. On all identified feeders we plug the vehicle counting module on which the vehicles are counted using video processing techniques as illustrated on fig 1.Once counted the value is transported in real time to the base station on which the cumulative tally of each subsection is obtained.

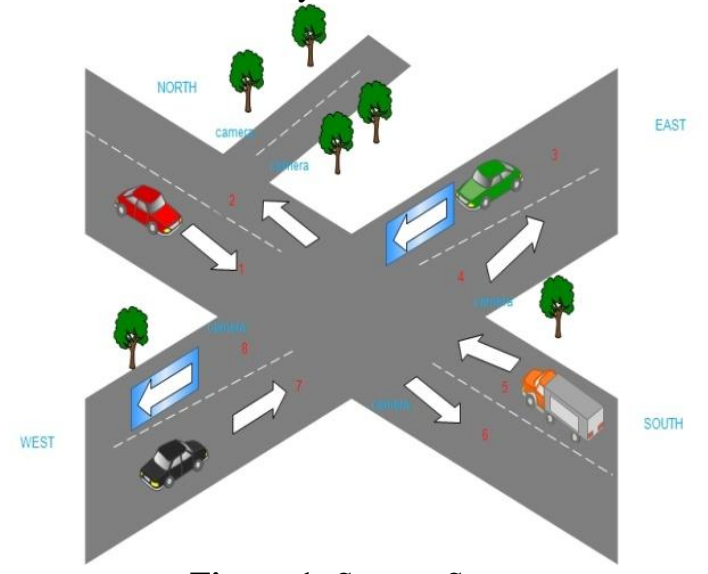

Figure 1: System Setup 


\section{International Journal of Science and Research (IJSR) \\ ISSN (Online): 2319-7064}

Index Copernicus Value (2013): 6.14 | Impact Factor (2015): 6.391

We designed and created a database that will keep the total tally of each substation at a particular time (t). The vehicles movement at a particular time in the system are subjected to twelve (12) vectors quantities such as NorthSouth(NS), North-East(NE), North-West(NW), East-West (EW), East-North(EN), East-South(ES), South-North (SN), South-West (SW), South-East(SE), West-East(WE), WestNorth(WN) and West-South (WS) as illustrated on fig. 1.

The traffic light junction comprises of four (4) traffic lights devices, each devices moves between four states which are Green, Yellow, Red and Green-Arc. The traffic light devices are uniquely identified through numbering; one traffic light device state determines the vehicle traffic status (VTS) of three lanes as illustrated on fig. 2.

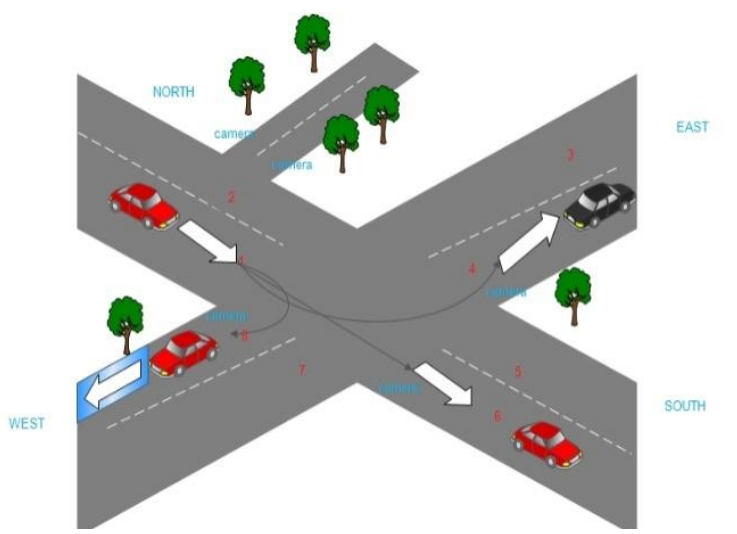

Figure 2: Vehicle Movement Possibilities

The proposed algorithm takes into consideration twelve vector quantities in the system, which traffic light device with its corresponding state at a particular time (t). By identifying a particular traffic light devices and its current state, we can use the counted vehicles value on a particular lane to add or subtract from the influenced lanes.

State (st): Green NorthSouth-SouthNorth (GNS-SN), Green EastWest-WestEast (GEW-WE), Green WestNorthEastSouth (GWN-ES), Green SouthWest-NorthEast (GSW-NE)

Lane Vehicle density: $\operatorname{lvd}_{\mathrm{i}=0, \ldots \ldots, 7}$.

Feed Count for lane: $\mathrm{fc}_{\mathrm{i}=0, \ldots \ldots ., 7 \text {. }}$

Drain count for lane: $\mathrm{dc}_{\mathrm{i}=0, \ldots \ldots \ldots, 7}$.

Levels: 0 - independent of Traffic light device states, 1depends on the traffic light states

1. Start

2. Initialize the lane vehicle densities : $\operatorname{lvd}_{\mathrm{i}=0, \ldots \ldots, 7}=$

3. Level: 0

i. $\quad \operatorname{lvd}_{\mathrm{i}}=\operatorname{lvd}_{\mathrm{i}}+\mathrm{fc}_{\mathrm{i}}$

ii. $\quad \operatorname{lvd}_{\mathrm{i}}=\operatorname{lvd}_{\mathrm{i}}-\mathrm{dc}_{\mathrm{i}}$

4. $\quad$ Level: 1

i. $\quad$ Get the state st

ii. If $\mathrm{st}=\mathrm{GNS}-\mathrm{SN}$

a. $\quad \operatorname{lvd}_{2}=\operatorname{lvd}_{2}+\mathrm{fc}_{2}$

b. $\quad \operatorname{lvd}_{6}=\operatorname{lvd}_{6}+\mathrm{fc}_{6}$

c. $\quad \operatorname{lvd}_{5}=\operatorname{lvd} \mathrm{d}_{5}-\mathrm{fc}_{2}$

$\begin{array}{ll}\text { d. } & \operatorname{lvd}_{1}=\operatorname{lvd}_{1}-\mathrm{fc}_{6} \\ \text { iii. } & \text { If st }=\mathrm{GEW}-\mathrm{WE} \\ \text { e. } & \operatorname{lvd}_{8}=\operatorname{lvd}_{8}+\mathrm{fc}_{8} \\ \text { f. } & \operatorname{lvd}_{4}=\operatorname{lvd}_{4}+\mathrm{fc}_{4} \\ \text { g. } & \operatorname{lvd}_{3}=\operatorname{lvd}_{3}-\mathrm{fc}_{8} \\ \text { h. } & \operatorname{lvd}_{1}=\operatorname{lvd}_{7}-\mathrm{fc}_{4} \\ \text { iv. } & \text { If st }=\mathrm{GWN}-\mathrm{ES} \\ \text { i. } & \operatorname{lvd}_{2}=\operatorname{lvd}_{2}+\mathrm{fc}_{2} \\ \text { j. } & \operatorname{lvd}_{6}=\operatorname{lvd}_{6}+\mathrm{fc}_{6} \\ \text { k. } & \operatorname{lvd}_{7}=\operatorname{lvd}_{7}-\mathrm{fc}_{2} \\ \text { l. } & \operatorname{lvd}_{3}=\operatorname{lvd}_{3}-\mathrm{fc}_{6} \\ \text { v. } & \mathrm{If} \mathrm{st}=\mathrm{GSW}-\mathrm{NE} \\ \text { m. } & \operatorname{lvd}_{4}=\operatorname{lvd}_{4}+\mathrm{fc}_{4} \\ \text { n. } & \operatorname{lvd}_{8}=\operatorname{lvd}_{8}+\mathrm{fc}_{8} \\ \text { o. } & \operatorname{lvd}_{5}=\operatorname{lvd}_{5}-\mathrm{fc}_{8} \\ \text { p. } & \operatorname{lvd}_{1}=\operatorname{lvd}_{1}-\mathrm{fc}_{4} \\ \text { vi. } & \mathrm{Go} \mathrm{to} \mathrm{i} \\ \text { 5. } & \mathrm{Finish}\end{array}$

\section{Results and Discussion}

The algorithm aims at increasing the area under surveillance while keeping track of the vehicle densities in various lanes and allocating the appropriate time intervals to the lanes. The algorithm extends the traffic density estimation coverage area beyond the traffic lights neighborhood to reflect the realistic situation on the roads. Many studies has been done on the issue of intelligent traffic lights systems and yields good results but the coverage area is confined to the traffic light neighborhood [1-2], [7-10]. The algorithm attained the fully coverage of the lanes and evaluate their vehicle densities. Vehicle traffic density is an area that attracts many researchers, various methodologies has been deployed to estimate the vehicle traffic density on the roads. In [12], the estimation of density is based on vehicles mobility patterns that are car-following model and two-fluid model. The density estimation is used to dynamically choose the transmission range. This approach could not estimate the density in free flow traffic due to the absence of interactions between vehicles. In [13], fluid dynamics and car following model are used to estimate the vehicle density. Nevertheless, these strategies could give inaccurate results about the density since the speed is not always related to the density of vehicles on the road. Our approach gives the real vehicle density available on the roads without depending on the factors as the car flow speed or car density on the roads.

\section{Conclusion}

Vehicle traffic density calculation is an essential component of intelligent traffic lights systems that aims to address the unrealistic time slot allocation for various roads segments. Due to vital role, once it is precisely evaluated it contributes to a more realistic vehicle traffic flow on various roads segments. For the evaluation to be realistic the coverage area should reflect the entire road segments and not on the traffic lights neighborhoods. The proposed algorithm evaluates the vehicle traffic density for various roads in real time and hence contributes to achieving a realistic intelligent traffic light system. 


\section{International Journal of Science and Research (IJSR) \\ ISSN (Online): 2319-7064}

Index Copernicus Value (2013): 6.14 | Impact Factor (2015): 6.391

\section{References}

[1] Madhavi Arora, V. K. Banga, "Real Time Traffic Light Control System", 2nd International Conference on Electrical, Electronics and Civil Engineering (ICEECE'2012), pp. 172-176, Singapore, April 28-29, 2012.

[2] Sabya sanchi kanojia, "Real -time Traffic light control and Congestion avoidance system", International Journal of Engineering Research and Applications (IJERA), pp.925-929, Vol. 2, Issue 2, Mar-Apr 2012.

[3] Muhammad Tayyab, "Implementation of Restoration Path Using AODV in VANETs" Master's Dissertation at Brunel University London, UK.

[4] Anthony J. Venables, "Evaluating Urban Transport Improvements", Journal of Transport Economics and Policy, Vol. 41, No.2, pp. 173-188, May, 2007.

[5] Tommy Gärling, Geertje Schuitema, "Travel Demand Management Targeting Reduced Private Car Use", Journal of Social Issues, Vol. 63, Issue 1, pp. 139-153, March 2007

[6] Papageorgiou M., Diakaki C., Dinopoulou V., Kotsialos, A., "Review of road traffic control strategies", Proceedings of IEEE, Vol. 91, Issue 12, pp. 2043-2067, November 2004.

[7] Georgios Vigos, Markos Papageorgioua, Yibing Wangb, "Real-time estimation of vehicle-count within signalized links", Journal of Transportation Research Part C: Emerging Technologies, Volume 16, Issue 1, pp.18-35, February 2008.

[8] Michael W. Szeto and Denos C. Gazis, “Application of Kalman Filtering to the Surveillance and Control of Traffic Systems", Journal of Transportation Science, vol. 6 pp.. 4419-439, November 1972.

[9] Ashwini Basavaraju, Senhalata Doddigarla, Navitha Naidu, Shruti Malgatti "Vehicle Density Sensor System to Manage Traffic", International Journal of Research in Engineering and Technology, Vol. 3 march 2014.

[10]Celil Ozkurt and Fatih Camci "Automatic Traffic Density Estimation and Vehicle Classification For Traffic Surveillance Systems Using Neural Networks." Mathematical and Computational Applications, Vol. 14, No. 3, pp. 187-196, 2009.

[11] Ms Promila Sinhamar "Intelligent Traffic Light Density Control using IR Sensors and Microcontroller" International Journal of Engineering and Advanced technology Research vol 2, Issue 2, March 2012.

[12] M. Artimy, "Local Density Estimation and Dynamic Transmission-Range Assignment in Vehicular, " IEEE Transactions on Intelligent Transportation Systems, vol. 8, no. 3, pp. 400-412, 2007.

[13] T. Umer, Z. Ding, B. Honary, and H. Ahmad, "Implementation of microscopic parameters for density estimation of heterogeneous traffic flow for VANET, " in Communication Systems Networks and Digital Signal Processing (CSNDSP), 2010 7th International Symposium on, 2010, pp. 66-70.

[14] Ashlesh Sharma, Aditya Dhananjay, Lakshminarayanan Subramanian, vipin jain "Traffic Density Estimation from a Highly 2 Noisy Sources"
Author Profile

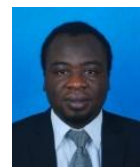

Juma Joram Mashenene is a Tutor at University of Dar Es Salaam Computing Centre. He received his B.E in Computer Science and Engineering from St. Joseph University in Tanzania in 2012 and current pursuing M.E in Signal and Information Processing from Tianjin University of Technology and Education. He is interested in Computer Vision, Embedded Systems and Cognitive Radio Networks as research Areas.

Xuewen Ding is an Associate Professor of Electrical Engineering School at Tianjin University of Technology and Education, and Director of Electrical Engineering Department. He received an M.S. in Signal and Information Processing from Tianjin University in 2003, and a PhD. in Signal and Information Processing from the same university in 2008. He worked as a visiting scholar at Oakland University in 2015. Dr. Ding is very actively involved in Intelligent Information Processing. His research areas include Computer vision, Machine learning and Real Time Systems

Said Kassim Katungunya, was born in Tanzania. He received B.E degree in Electrical and Electronics Engineering from Acharya Institute of Technology, India in2009. Currently he Pursue Master's degree in Signals and Information Processing at Tianjin University of Technology and Education, China. Also he hold CISCO certifications in CCNA security and CCNP routing and switching. From 2010 to 2013, He worked as a Network Engineer before joined Tianjin University of Technology and Education. His research interests include machine learning, artificial intelligence, pattern recognition and biomedical image processing. 